\title{
A ACEITABILIDADE DA RESERVA DO POSSÍVEL PELO PODER JUDICIÁRIO BRASILEIRO: LIMITE OU POSSIBILIDADE PARA OS GESTORES DA EDUCAÇÃO PÚBLICA?
}

\section{THE ACCEPTABILITY OF POSSIBLE RESERVE BY THE BRAZILIAN JUDICIARY: LIMIT OR POSSIBILITY FOR MANAGERS OF PUBLIC EDUCATION?}

\section{LA ACEPTABILIDAD DE LA RESERVA DE LO POSIBLE POR EL PODER JUDICIAL BRASILERO: ¿LIIMITE O POSIBILIDAD PARA LOS GESTORES DE LA EDUCACIÓN PÚBLICA?}

\author{
FLACH, Simone de Fátima \\ eflach@uol.com.br \\ UEPG - Universidade Estadual de Ponta Grossa \\ FLACH, Amanda Cristhina \\ amanda.c.flach@hotmail.com \\ UEPG - Universidade Estadual de Ponta Grossa
}

\begin{abstract}
RESUMO A partir de análise bibliográfica e documental, de cunho qualitativo, este texto apresenta como o princípio da reserva do possível tem sido utilizado como justificativa pelo poder público para a inexecução de preceitos legais para com as políticas sociais. Tendo como foco a educação, este artigo expõe sobre o direito à educação na legislação brasileira, responsabilidades dos gestores públicos nas diversas esferas administrativas e como o princípio da reserva do possível tem ou não encontrado guarida junto ao poder judiciário tornando-se matéria jurisprudencial. Ao final, conclui-se que, no campo das discussões e das interpretações legais, o poder judiciário pode tornar-se legitimador da inexecução das responsabilidades públicas.
\end{abstract}

Palavras-chave: Cláusula da reserva do possível. Direito à educação. Direitos sociais. Políticas sociais.

ABSTRACT From a bibliographical and documentary analysis of qualitative nature, this text presents how the principle of possible reserve has been used as a justification by the government for the non-performance of legal provisions for social policies. With education as focus, this paper analyzes the right to education in the Brazilian law, and the responsibilities of public administrators in various administrative spheres. In addition, it analyzes how the principle of possible reserve has or has not found shelter with the judiciary power becoming a jurisprudential matter. Finally, results lead the conclusion that, in the field of legal discussions and interpretations, the judiciary can become the legitimator of the non-performance of public responsibilities.

Keywords: Provision of possible reserve. Right to education. Social policies. Social rights.

RESUMEN A partir del análisis bibliográfico y documental, de cuño cualitativo, este texto presenta cómo el principio de la reserva de lo posible ha sido utilizado como 


\section{Atos de Pesquisa em Educação - ISSN 1809-0354 \\ Blumenau, v. 13, n.1, p.66-84, jan./abr. 2018 \\ DOI: http://dx.doi.org/10.7867/1809-0354.2018v13n1p66-84}

justificativa por el poder público para el incumplimiento de requisitos legales para con las políticas sociales. Con foco en la educación, este artículo expone sobre el derecho a la educación en la legislación brasilera, responsabilidades de los gestores públicos en las diversas esferas administrativas y cómo el principio de la reserva de lo posible ha o no encontrado guarida junto al poder judicial volviéndose materia jurisprudencial. Al final, se concluye que, en el campo de las discusiones y de las interpretaciones legales, el poder judicial puede hacerse legitimador del incumplimiento de las responsabilidades públicas.

Palabras-clave: Cláusula de la reserva de lo posible. Derecho a la educación. Derechos sociales. Políticas sociales.

\section{INTRODUÇÃO}

A efetivação do direito à educação no Brasil, em seus diversos níveis e modalidades, tem se constituído como um grande desafio para toda a sociedade, visto que a questão é eivada por inúmeros limites, tanto de cunho cultural e econômico quanto político. A ampliação do direito à educação nos diplomas legais do final do século XX e início do XXI expressa uma conquista histórica da sociedade brasileira, principalmente da camada mais pobre da população e, ao mesmo tempo, traz em seu bojo a ampliação de responsabilidades do poder público para sua efetivação.

A partir da última década do século $X X$, impulsionado pelo processo de redemocratização, reorganização política, acordos internacionais celebrados ${ }^{1} \mathrm{e}$ orientações de organismos multilaterais ${ }^{2}$, houve a reestruturação do arcabouço legal brasileiro para a educação e a implementação de políticas públicas para o setor. Os compromissos assumidos expuseram a necessidade de efetivar o direito à educação não apenas em relação ao acesso, mas, sobretudo, na perspectiva da qualidade do processo educativo, de forma a possibilitar a permanência e a aprendizagem dos

\footnotetext{
1 É importante destacar que o Brasil recebeu influência da Declaração dos Direitos do Homem, de 1948 e é signatário de diversos acordos internacionais que têm foco, dentre outras questões, a educação. Dentre tais acordos, destacamos: a Convenção Relativa à Luta contra a Discriminação no Campo do Ensino, de 1960; Acordo de Ponta de Leste, de 1961 e de Santiago, 1962, o Pacto Internacional dos Direitos Econômicos, Sociais e Culturais, de 1966; Declaração Mundial de Educação para Todos, de 1990 e Declaração de Salamanca, de 1994.

2 Dentre as influências dos Organismos Multilaterais, destacamos o papel desempenhado pela CEPAL - Comissão Econômica para a América Latina e Caribe, cujas orientações estão no âmbito da reestruturação produtiva; UNESCO - Organização das Nações Unidas para a Educação, a Ciência e a Cultura, que tem elaborado uma série de documentos que oferecem sustentáculo às reformas educacionais empreendidas após 1990 e a reforma educativa proposta pelo Banco Mundial a partir de 1995, por meio de documentos e convênios.
} 


\section{Atos de Pesquisa em Educação - ISSN 1809-0354 \\ Blumenau, v. 13, n.1, p.66-84, jan./abr. 2018 \\ DOI: http://dx.doi.org/10.7867/1809-0354.2018v13n1p66-84}

alunos. Nesse sentido, a legislação sofreu inúmeras alterações: incorporação da Educação Infantil no campo educacional; maior abrangência do ensino obrigatório, de forma a atender crianças e adolescentes de 4 a 17 anos de idade; indicações para a ampliação do tempo de permanência diário na escola por meio da educação de tempo integral; necessidade de melhoria da formação, da carreira e da remuneração dos profissionais da educação; atendimento educacional especializado para aqueles que assim necessitarem, dentre outros.

Todavia, todo o arcabouço legal reorganizado não foi capaz de garantir a efetividade de suas previsões, expondo a lacuna existente entre a previsão e a realidade para a implementação de políticas educacionais que contribuíssem na superação das desigualdades educacionais no país. Além do papel desempenhado pelos poderes legislativo e executivo nesse processo, entra em cena o poder judiciário, na qualidade de fiscal da execução das previsões legais, pressionando a administração pública nas diversas esferas administrativas para que o arcabouço legal seja aplicado com rigor.

A resposta da administração pública, no limite do cumprimento legal, expõe a desigualdade de arrecadação tributária e sua consequente redistribuição entre os entes administrativos responsáveis pela oferta educacional e tem impulsionado o debate em torno do financiamento público para a educação, abrindo portas para as parcerias público-privadas, com o objetivo explícito de cumprir as metas educacionais a partir de um modelo de gestão que tem em seu bojo a desresponsabilização do poder público para com as políticas sociais. Nesse contexto, a responsabilidade dos gestores públicos pela garantia do direito à educação precisa ser constantemente revisitada.

Para além dessas questões, outra discussão permeia a efetivação do direito à educação: a discussão sobre o papel dos poderes da União, no contexto republicano, os quais devem, segundo preceito constitucional, ser independentes e harmônicos entre si. Explicitar a correlação de forças existente entre os poderes legislativo, executivo e judiciário e as necessidades da população é um dos objetivos que permeia o presente texto, visto que o poder responsável pela oferta educacional tem procurado justificativa plausível para o não cumprimento de sua obrigação constitucional para com o direito à educação. É nessa seara controversa de 
garantias e deveres que a cláusula da reserva do possível entra para o debate sobre as possibilidades de aplicação da legislação educacional.

A partir de pesquisa bibliográfica e documental, de cunho qualitativo, o presente texto expõe sobre o direito à educação na legislação brasileira, as responsabilidades dos gestores públicos nas diversas esferas administrativas e como a cláusula da reserva do possível, originada no direito alemão, tem sido utilizada como justificativa para o não cumprimento das previsões legais e determinações judiciais para o setor educacional. Dessa forma, indica-se que há um conturbado conflito entre as disposições legais, as determinações do poder judiciário e as possibilidades financeiras do poder executivo para a garantia do direito à educação. Nesse contexto de discussões sobre interpretação legislativa, quem mais sofre é o cidadão brasileiro.

\section{A POSITIVAÇÃO DO DIREITO À EDUCAÇÃO NO BRASIL: INDICATIVOS PARA A SUA GARANTIA}

O reconhecimento da educação enquanto direito fundamental de natureza social pela Constituição da República de 1988 representa compromissos a serem assumidos pelo Estado Brasileiro, os quais se materializarão (ou não) em políticas públicas voltadas para a área educacional. No entanto, a efetivação do direito assegurado se entrelaça à organização do Estado e, por isso, expressa contradições em relação às diferentes concepções e compromissos que nortearão as ações governamentais.

Convém ressaltar que entendemos Estado como a unidade entre sociedade civil e sociedade política ${ }^{3}$, e que os interesses desses segmentos se materializam em ações governamentais. As ações governamentais atingem seus fins por meio de políticas públicas, as quais no campo da educação visam, em geral, resolver questões educacionais como garantir o acesso e a permanência de alunos nas instituições de educação básica e superior; e, ainda, alçar melhores patamares de

\footnotetext{
${ }^{3}$ Aqui utilizamos a concepção gramsciana de Estado Ampliado, segundo a qual o Estado que "habitualmente, é entendido como sociedade política" se expressa no "equilíbrio da sociedade política com a sociedade civil" por meio da "hegemonia de um grupo social sobre toda a sociedade nacional" (GRAMSCl, 2005, p. 84). Por isso, embora por força de lei o Estado devesse agir em prol do bem comum, os compromissos assumidos pelos grupos que assumem o poder se vinculam aos interesses hegemônicos.
} 
Atos de Pesquisa em Educação - ISSN 1809-0354

Blumenau, v. 13, n.1, p.66-84, jan./abr. 2018

DOI: http://dx.doi.org/10.7867/1809-0354.2018v13n1p66-84

qualidade da educação (seja nos processos de ensino ou nos resultados da aprendizagem).

Em que pese os interesses em disputa na seara política, o significado histórico-social da educação como direito social assegurado à toda a população de determinado país é incomensurável. Para a população brasileira, essa conquista é o resultado de um processo difícil, marcado por reivindicações sociais que se materializaram em avanços e retrocessos nas diversas Constituições e legislações infraconstitucionais, as quais previram o direito à educação vinculado aos compromissos políticos e interesses de classe de cada momento histórico. Ainda, além das previsões constitucionais e legais, as práticas político-educacionais foram definidoras da efetivação ou não das previsões. Esse processo contraditório de materialização do direito à educação está entrelaçado à constituição da cidadania do povo brasileiro.

Expor como o direito à educação no Brasil se constitui na qualidade de direito fundante de cidadania extrapola a possibilidade do presente texto. No entanto, é necessário indicar que, a partir do processo de redemocratização brasileira, a Constituição de 1988 anuncia a instituição de um Estado Democrático de Direito, destinado a assegurar, dentre outros preceitos, o exercício dos direitos sociais e individuais como valores supremos de uma sociedade.

O Estado Democrático de Direito previsto no parágrafo único do art. $1^{\circ}$ da Constituição assim expressa: "Todo o poder emana do povo, que exerce por meio de representantes eleitos ou diretamente, nos termos desta Constituição" (BRASIL, 1988, p. 3). Ao declarar que "todo poder emana do povo", a Constituição assegura de forma ampla a soberania popular, dando centralidade ao poder do cidadão brasileiro e indicando ser ele sujeito responsável pelos destinos do país. Para tanto, a Carta Magna torna todos iguais por direito, colocando o princípio da isonomia como precursor e resultado da cidadania.

Sendo o ordenamento jurídico primeiro, a partir do qual se fundamentam todas as demais leis e normatizações, a Constituição assume papel de destaque no ordenamento legal no País. Não é sem sentido que, na Carta Magna, foi prevista uma seção específica intitulada "Da educação", para tratar sobre as questões educacionais. No entanto, é preciso destacar que os dispositivos relacionados à 
oferta e à garantia da educação não estão circunscritos apenas ao capítulo específico, mas são previstos em inúmeros outros pontos do texto constitucional, ora de forma clara e direta (ex.: capítulo "Da Educação"), ora de forma dispersa (ex.: previsão de competências dos entes federados) ou, ainda, de forma indireta, quando não se referem diretamente à educação, mas influenciam a proteção dos direitos educacionais (ex.: Mandado de Segurança).

Mesmo antes do capítulo que trata especificamente da Educação, a Constituição assim assinala em seu art. 60: "São direitos sociais a educação, a saúde, o trabalho, o lazer, a segurança, a previdência social, a proteção à maternidade e à infância, a assistência aos desamparados, na forma desta Constituição" (BRASIL, 1988, p. 12). É importante destacar que os direitos sociais previstos na constituição são aqueles que, quando amplamente garantidos pelo poder público, oferecem possibilidade de superação das desigualdades sociais históricas que marcam o povo brasileiro e, consequentemente, conferem ao indivíduo o pleno exercício de direitos, visto que garantem a ele condições de vida digna e possibilidades para a intervenção ativa na realidade.

A partir da disposição constitucional, que coloca a educação como o primeiro direito social na ordem das citações, a educação emerge como um direito social que dá sustentação ao exercício da cidadania. Ousamos dizer que, sem a educação usufruída em toda a sua plenitude, não existe cidadania. No mesmo sentido, o pleno exercício da democracia encontrar-se-á entravado se esse direito social não for garantido à população. Cury (2002) aponta, ainda, outros direitos assegurados constitucionalmente, mas que dependem de que o direito à educação seja efetivado.

É importante se saber, por exemplo, que o Título II, Capítulo I, art. $5^{\circ}$ da nossa Constituição garante uma lista infinda de direitos civis dentre os quais muitos têm a ver com educação. Cito alguns: a igualdade jurídica entre homem e mulher, a liberdade de consciência e de expressão, a liberdade de associação, a condenação a todo tipo de maus-tratos e a condenação ao racismo como crime inafiançável (CURY, 2002, p. 19).

Assim sendo, a educação positivada e colocada como direito de todos e dever do Estado e da família é entendida como primordial para o desenvolvimento do ser humano, para que este exerça plenamente a cidadania, reunindo as condições necessárias para entender, resistir e protagonizar em conjunto com outros homens 
as transformações sociais, políticas e econômicas necessárias para uma vida digna, justa e pautada na igualdade. O status dado à educação é tão importante que o ensino gratuito e obrigatório se tornou direito público subjetivo nos termos do art. 208, da Constituição de 1988, podendo o gestor público responsável, no caso de não atendimento, ser enquadrado em "crime de responsabilidade".

Para garantia do direito à educação, a Constituição Federal, no limite do regime de colaboração entre os entes federados, adota o posicionamento de repartição de responsabilidades ou distribuição de competências nos termos do art. 211, questão reafirmada nos artigos $9^{\circ}$ ao 11 da Lei de Diretrizes e Bases da Educação Nacional - Lei nº 9.394/96.

Embora os dispositivos constitucionais efetivem-se na materialidade social conforme os interesses de classe, é preciso compreender que eles demonstram uma intencionalidade, dando indicativos para a efetivação do direito à educação na atualidade. Na esfera judicial, existem mecanismos que têm a função de garantir que os ditames constitucionais e infraconstitucionais sejam colocados em prática. Dentre esses mecanismos, podemos citar, com base na Constituição Federal (BRASIL, 1988): a) mandado de segurança para "proteger direito líquido e certo" nos termos dos incisos LXIX e LXX do art. 5; b) Mandado de Injunção, conforme inciso LXXI do art. 5; e c) Ação Civil Pública, nos termos do art. 129.

Entendida como direito fundamental, a educação é alçada à categoria de "direito público subjetivo" e, como tal, caracteriza-se por prevalecer sobre os interesses privados, ou seja, o valor social global do direito sobrepõe-se, pois sua efetividade atinge toda a sociedade e não apenas determinado indivíduo.

Em linhas gerais, "[...] o direito subjetivo representa a possibilidade de se exigir, como próprios, uma prestação, ou um ato de maneira garantida, nos limites atributivos das regras de direito" (REALE, 1988, p. 261). Nesse sentido, entender a educação como direito público subjetivo implica afirmar que o indivíduo possui uma esfera de ação inviolável, na qual o Poder Público não pode penetrar. Assim, são esclarecedoras as palavras de Reale (1988, p. 264, grifos do autor), quando ele afirma que "[...] no fundo, todos os direitos públicos subjetivos pressupõem o direito fundamental de liberdade, entendida em sua dupla valência, como poder autônomo de ser e agir na esfera privada (liberdade civil) e na esfera pública (liberdade 
política)". Direito público subjetivo é, portanto, "[...] aquele pelo qual o titular de um direito pode exigir direta e imediatamente do Estado, o cumprimento de um dever e de uma obrigação" (CURY, 2002, p. 21).

$\mathrm{Na}$ seara educacional, o direito público subjetivo cria a possibilidade de o titular do direito agir de forma a reivindicar ao poder público a garantia do direito à educação. O titular desse direito é uma pessoa de qualquer idade que tem impedido ou limitado o acesso à Educação Básica obrigatória e que pode e deve buscar, junto ao ente administrativo responsável pela oferta, ações concretas que o garantam. Assim, esse direito pode ser exigido por "[...] qualquer cidadão, grupo de cidadãos, associação comunitária, organização sindical, entidade de classe ou outra legalmente constituída e, ainda, o Ministério Público” (BRASIL, 1996, p. 27833) conforme previsto no art. $5^{\circ}$ da Lei 9394/96.

A previsão constitucional e infraconstitucional representa a possibilidade de o cidadão exigir da autoridade competente que o seu direito seja efetivamente garantido sob pena de essa autoridade sofrer as sanções referentes ao seu não cumprimento. Nessa perspectiva, o direito assegurado pelo arcabouço legal dá indicativos sobre a responsabilidade e a necessidade de sua garantia, prevendo sanções pelo seu não cumprimento. Em uma sociedade de tradição romanística, como é o caso da sociedade brasileira, o direito à educação assegurado não pode ser substituído ou alterado conforme os interesses do poder público, ganhando força o direito positivado4. Essa é uma questão extremamente importante na esfera educacional, visto que a oferta de educação sempre esteve atrelada aos interesses dominantes de uma minoria, e dar a possibilidade de que a maioria exerça essa ação é um pequeno passo para a efetivação da cidadania no contexto brasileiro.

Assim, a utilização pelo poder público de justificativa para o não cumprimento da obrigação educacional por meio da cláusula da reserva do possível pode fraudar a efetivação da educação como direito de cidadania de toda a população, visto que tem figurado nos argumentos dos gestores públicos responsáveis pela oferta

\footnotetext{
${ }^{4}$ É importante esclarecer que, na tradição romanística, à qual se filiam nações latinas e germânicas, a característica fundamental do direito é o processo legislativo, em detrimento às demais fontes (tais como usos e costumes). Segundo Venosa (2009, p. 122) sob a luz desse sistema, "a lei prepondera como o centro gravitador do Direito", sendo codificada e utilizada como eixo fundamental do raciocínio jurídico. No contexto de luta pela manutenção do direito à educação em sociedades desiguais como a brasileira, os dispositivos legais assumem relevância inconteste, visto que apontam para garantias educacionais e, consequentemente, para o exercício da cidadania.
} 
educacional. O entendimento do poder judiciário referente a outros direitos sociais é controverso nas Cortes Brasileiras e vem se materializando em decisões divergentes que ora validam as justificativas, ora as repudiam e obrigam o poder público ao cumprimento irrestrito das determinações constitucionais. No entanto, essa justificativa tem ganhado espaço na discussão jurídica e político-educacional, constituindo-se em possibilidade latente de acolhimento pelo poder judiciário. Compreender a questão, como campo controverso entre o direito da população à educação e a possibilidade de seu cumprimento pelo poder público, é um dos desafios impostos para os estudantes, pesquisadores da área educacional e para a sociedade como um todo.

\section{AS CONTROVÉRSIAS NA DISCUSSÃO SOBRE O PRINCÍPIO DA RESERVA DO POSSÍVEL}

A educação como direito do cidadão e dever do Estado esteve presente em maior ou menor medida nos textos constitucionais brasileiros conforme os interesses políticos de cada momento histórico. Em 1988, sob a influência de interesses contraditórios, o Brasil teve uma Constituição elaborada sob os limites de uma organização de Estado Democrático de Direito ainda não consolidado. Uma Constituição não se elabora ao simples prazer dos legisladores, mas representa as reivindicações, as aspirações dos diversos segmentos da sociedade. Ela representa o resultado das correlações de forças, muitas vezes antagônicas, que refletem a vontade de uma nação. Isso ficou evidenciado, também, no caso brasileiro. Nesse sentido,

A Constituição de 1988 tentou dar conta das profundas mudanças ocorridas em nosso país, na economia, nas relações de poder e nas relações sociais globais, nos últimos 20 anos, introduzindo temas, redefinindo papéis, incorporando às instituições sociais segmentos historicamente marginalizados, sem, no entanto, alterar substantivamente as relações sociais vigentes (NEVES, 1999, p. 99).

Isso se justifica devido ao empenho do governo da época em direcionar suas ações baseadas em um discurso de "tudo pelo social", além de ter o compromisso em romper com as amarras do militarismo ainda presente. Por isso, o texto constitucional está repleto de preceitos que indicam a valorização ao cidadão como 
Atos de Pesquisa em Educação - ISSN 1809-0354

Blumenau, v. 13, n.1, p.66-84, jan./abr. 2018

DOI: http://dx.doi.org/10.7867/1809-0354.2018v13n1p66-84

sujeito de direitos e responsabilizam de maneira contundente o poder público, além de clamar pela participação da sociedade, tornando-a corresponsável pelas ações.

Em que pese o texto constitucional estar repleto de preceitos a serem seguidos pelos cidadãos e pelo poder público, o cerne da discussão ainda reside na efetividade dos direitos previstos. Entre a previsão constitucional e o verdadeiro exercício de todos os preceitos, existem barreiras sociais, culturais e econômicas, as quais são determinantes tanto para os cidadãos quanto para a administração pública responsável pela implementação das previsões. No âmbito da administração pública, a barreira da disponibilidade de recursos tem sido recorrente nos argumentos dos gestores para a implementação de ações que garantam o direito previsto.

Analisando o texto constitucional, o artigo $5^{\circ}, \S 1^{\circ}$ elucida que: "As normas definidoras dos direitos e garantias fundamentais têm aplicação imediata" (BRASIL, 1988, p. 12). Tal artigo demonstra que, em razão do direito à educação estar inserido no Título dos Direitos e Garantias Fundamentais, a aplicabilidade imediata se estende a todos os direitos fundamentais, incluindo o direito à educação. Nesse sentido, são esclarecedoras as palavras de Sarlet:

Com base no exposto, e partindo da premissa de que não há como tomar a sério os direitos fundamentais se não se levar a sério o disposto no art. $5^{\circ}, \S$ $1^{\circ}$, de nossa Constituição, constata-se, desde logo, a necessidade de não subestimarmos (nem superestimarmos) o significado e alcance desta norma (SARLET, 2012, p. 236).

Para além da previsão constitucional que determina a imediata efetivação do direito à educação, é preciso considerar que, em alguns casos, o poder público pode encontrar dificuldades em materializar tal questão. Como justificativa à inexecução dos preceitos constitucionais, o poder público tem utilizado a justificativa pautada na "cláusula da reserva do possível”, buscando no poder Judiciário uma saída para sua abstenção.

A Cláusula da Reserva do Possível, como instituto jurídico, teve sua origem na Alemanha, na década de 1970, quando a Corte daquele país, em decisão sobre restrição de vagas em universidades, entendida como restrição aos direitos fundamentais sociais, afirmou que sua ampliação estaria sujeita ao que se convencionou chamar de "cláusula da reserva do possível", ou seja, que a ação do 


\title{
Atos de Pesquisa em Educação - ISSN 1809-0354 \\ Blumenau, v. 13, n.1, p.66-84, jan./abr. 2018 \\ DOI: http://dx.doi.org/10.7867/1809-0354.2018v13n1p66-84
}

Estado estava condicionada à razoabilidade da pretensão e à possibilidade disponível. Como o atendimento pleiteado estava sendo ofertado em número razoável às necessidades locais, a oferta não se tornava obrigatória (MÂNICA, 2011).

Ao analisar a questão, Mânica (2011, p. 11) afirma que a cláusula da reserva do possível "[...] não se refere direta e unicamente à existência de recursos materiais suficientes para a concretização do direito social, mas à razoabilidade da pretensão deduzida com vistas a sua efetivação". No entanto, no Brasil, a questão orienta a justificativa do poder público com o intuito de condicionar a efetivação e garantia dos direitos fundamentais à prévia existência de recursos financeiros para sua concretização. Segundo Mânica (2011), o argumento utilizado centra-se na justificativa de que o poder público só efetivará determinado direito fundamental se houverem recursos financeiros disponíveis para tanto.

\begin{abstract}
A teoria da reserva do possível, portanto, tal qual sua origem, não se refere direta e unicamente à existência de recursos materiais suficientes para a concretização do direito social, mas à razoabilidade da pretensão deduzida com vistas a sua efetivação. Entretanto, a interpretação e transposição que se fez de tal teoria, especialmente em solo pátrio, fez dela uma teoria da reserva do financeiramente possível, na medida em que se considerou como limite absoluto à efetivação de direitos fundamentais sociais (i) a suficiência de recursos públicos e (ii) a previsão orçamentária da respectiva despesa (MÂNICA, 2011, p. 11).
\end{abstract}

Em que pese a justificativa de insuficiência de recursos financeiros para a garantia do direito à educação ser plausível no atual contexto econômico, ao analisar a questão, Silva (2011) indica que é possível constatar que o poder público se vale desse preceito com o intuito de ludibriar o cidadão e não concretizar o direito à educação com o "simples argumento" da ausência de recursos disponíveis. Ainda, nesse sentido:

Condicionar a efetivação dos direitos fundamentais sociais unicamente à existência ou não de recursos disponíveis e, consequentemente, à decisão do administrador, causa uma grande insegurança jurídica, razão pela qual as escolhas realizadas por este devem ser sempre precedidas de uma análise cautelosa do caso concreto, visando sempre a melhor decisão possível para o conflito de interesses (SOUZA, 2013, s/p).

Segundo Wang (2008), a escassez de recursos não pode ser considerada como limite fático à efetivação dos direitos fundamentais e sociais, já que estão 


\section{Atos de Pesquisa em Educação - ISSN 1809-0354 \\ Blumenau, v. 13, n.1, p.66-84, jan./abr. 2018 \\ DOI: http://dx.doi.org/10.7867/1809-0354.2018v13n1p66-84}

presentes nas obrigações dos Estados e Municípios. Se os direitos sociais, como é o caso da educação, estivessem condicionados exclusivamente à existência de recursos financeiros disponíveis pelo poder público, este estaria desobrigado de efetivá-los pelo simples argumento da impossibilidade financeira. Concordamos com Silva (2011) que esse argumento não apenas é falho, como vai de encontro aos interesses da coletividade e dos preceitos constitucionais. Contudo, tal justificativa tem sido utilizada pelo poder púbico para desobrigá-lo da responsabilidade que lhe é atribuída.

A questão acerca da reserva do possível e a concretização do direito à educação é complexa e demanda a análise dos princípios constitucionais. Para exemplificar a questão, citamos o caso do Município de Criciúma que foi condenado, em segunda instância, a criar vaga em creche para que o direito à educação fosse efetivado. Irresignado com tal determinação judicial, o referido Município interpôs Recurso Especial ao Superior Tribunal de Justiça, utilizando como argumento central a ausência de recursos financeiros pautada na reserva do possível (REsp 1.185.474 - SC). Na época em que foi prolatado o acórdão (2010), o Ministro Humberto Martins entendeu que deveria ser levada em consideração a escassez de recursos e que a ausência de previsão orçamentária do poder público não era argumento infundado. No teor da decisão, ele ressaltou que os direitos fundamentais não são uma escolha do governante, mas um dever; no entanto ele está condicionado à suficiência orçamentária. Como solução à questão recursal, o Ministro indicou a comprovação documental sobre a verdadeira insuficiência de recursos e impossibilidade de efetivação do direito à educação sob pena de que a alegação da reserva do possível fosse considerada desculpa infundada. Como no caso em tela não houve qualquer prova da insuficiência financeira, o recurso foi improvido, mantendo-se a decisão recorrida a fim de determinar o acesso à creche dos menores de zero aos seis anos de idade:

É por esse motivo que, em um primeiro momento, a reserva do possível não pode ser oposta à efetivação dos Direitos Fundamentais, já que, quanto a estes, não cabe ao administrador público preteri-los em suas escolhas. Nem mesmo a vontade da maioria pode tratar tais direitos como secundários. Isso, porque a democracia não se restringe na vontade da maioria [...] Com isso, observa-se que a realização dos Direitos Fundamentais não é opção do governante, não é resultado de um juízo discricionário nem pode ser encarada como tema que depende unicamente da vontade política. Aqueles 
Atos de Pesquisa em Educação - ISSN 1809-0354

Blumenau, v. 13, n.1, p.66-84, jan./abr. 2018

DOI: http://dx.doi.org/10.7867/1809-0354.2018v13n1p66-84

direitos que estão intimamente ligados à dignidade humana não podem ser limitados em razão da escassez quando esta é fruto das escolhas do administrador [...]. Todavia, a real insuficiência de recursos deve ser demonstrada pelo Poder Público, não sendo admitido que a tese seja utilizada como uma desculpa genérica para a omissão estatal no campo da efetivação dos direitos fundamentais, principalmente os de cunho social (STJ, 2010).

Verifica-se, portanto, que, no caso analisado, apesar de o poder público invocar a reserva do possível como justificativa à inexecução do direito à educação, ainda que o poder Judiciário entenda plausível a discussão acerca da ausência de dotação orçamentária, faz-se necessária a comprovação da impossibilidade de efetivação do direito.

No entanto, em que pese existir decisão judicial reconhecendo como válida a alegação da reserva do possível, ainda assim o poder Judiciário tem prolatado decisões que não só determinam que o poder público efetive o direito à educação independentemente de reserva financeira, como determina inclusive o bloqueio de valores dos cofres públicos para atendimento de tal direito.

É justamente o que se evidencia em decisão de Agravo de Instrumento proferida pelo Tribunal de Justiça do Rio Grande do Sul no ano de 2014 (Al 70062590989 - RS). No referido caso, o município de Porto Alegre não estava cumprindo com a determinação constitucional de garantir escola à determinada criança em razão da inexistência de vaga disponível. Partindo da premissa de que a educação é direito de todos, os genitores da criança ingressaram com ação judicial a fim de que o poder público fosse condenado a arcar com o pagamento de mensalidade de creche particular. Houve decisão liminar determinando que o município de Porto Alegre custeasse parte da mensalidade escolar pelo período de três meses. Tal decisão determinou o bloqueio de $\mathrm{R} \$ 1.050,00$ (um mil e cinquenta reais) dos cofres públicos municipais para custear as despesas escolares.

Entretanto, como os pais da criança não possuíam condições financeiras de arcar sequer com parte da mensalidade da creche, eles interpuseram Agravo de Instrumento cuja decisão determinou o pagamento integral da mensalidade pelo município. A Desembargadora, relatora da questão, entendeu que, quando tratar-se de direito à educação, não cabe alegação da reserva do possível por tratar-se de direito constitucionalmente previsto e de absoluta prioridade. Ressaltou, ainda, que o 
direito à educação se sobrepõe a qualquer outro valor afastando as teses do poder público de ausência de recursos financeiros:

[...] vê-se da impossibilidade econômica dos responsáveis legais da menor em custear a parcela que lhe foi imposta, por força de decisão judicial, uma vez que necessitam trabalhar, não tendo condições de custear tal despesa (fl. 19/20 e 22v.). Portanto, sendo a educação um direito social, previsto constitucionalmente, e que deve ser assegurado com absoluta prioridade em relação às crianças e adolescentes, incumbe ao Poder Público a responsabilidade de garantir seus acessos nas escolas ou creches, como no caso. O exercício pleno do direito à educação, além da vaga na escola. Por fim, não é demais lembrar, ainda, que as normas protetivas da Fazenda Pública não podem prevalecer ante garantias fundamentais previstas constitucionalmente; pelo contrário, o direito à educação sobrepõe-se a qualquer outro valor, o que afasta, igualmente, quaisquer teses relativas à falta de previsão orçamentária, como a escassez de recursos (TJ-RS, 2014).

Verifica-se, portanto, que, da análise dos julgados mencionados, a educação vem sendo entendida como prioritária frente aos argumentos da Reserva do Possível, o que demonstra a preocupação e o compromisso do Poder Judiciário com a efetivação desse direito fundamental.

Conforme evidenciado, a Reserva do Possível apresenta-se como uma desculpa para a ineficiência estatal e para a não concretização do direito à educação, demonstrando que a intervenção do Poder Judiciário é imprescindível para fazer valer os ditames constitucionais. Caso o argumento da impossibilidade financeira da União, dos Estados e Municípios fosse acolhida pelo Judiciário, a educação não passaria de mera disposição legal e sem qualquer aplicabilidade prática, dificultando cada vez mais o acesso à educação e aos meios necessários à sua garantia.

No entanto, é de considerar-se que esse argumento da Reserva do Possível não é rechaçado em toda e qualquer hipótese relacionada à concretização de direitos. Pelo contrário, evidenciou-se a existência de julgados que acolhem a tese da impossibilidade financeira do Estado quando se está diante de alguns direitos econômicos, sociais e culturais.

Em decisão de Medida Cautelar de Arguição de Descumprimento de Preceito Fundamental, o Ministro Celso de Mello ponderou que:

É que a realização dos direitos econômicos, sociais e culturais - além de caracterizar-se pela gradualidade de seu processo de concretização - 
Atos de Pesquisa em Educação - ISSN 1809-0354

Blumenau, v. 13, n.1, p.66-84, jan./abr. 2018

DOI: http://dx.doi.org/10.7867/1809-0354.2018v13n1p66-84

depende, em grande medida, de um inescapável vínculo financeiro subordinado às possibilidades orçamentárias do Estado, de tal modo que, comprovada, objetivamente, a incapacidade econômico-financeira da pessoa estatal, desta não se poderá razoavelmente exigir, considerada a limitação material referida, a imediata efetivação do comando fundado no texto da Carta Política (STF, 2004).

Verifica-se, portanto, que, em alguns casos, em especial aqueles que tratam de direitos econômicos, sociais e culturais, é possível a arguição de impossibilidade financeira de cumprimento, não se tratando de ofensa aos direitos constitucionais.

Esse entendimento foi verificado em caso em que o Ministério Público do Estado do Paraná ingressou com ação civil pública requerendo que o Município de Cambará destinasse um imóvel para a instalação e abrigo de menores carentes, deixando ainda à disposição recursos materiais e humanos.

Nesse caso, o Superior Tribunal de Justiça entendeu que o Município tem competência suficiente para determinar onde será aplicado o dinheiro público e quais áreas são prioritárias. Para tanto, utilizou como fundamento os ensinamentos de Meirelles:

Na lição de Hely Lopes Meirelles, "só o administrador, em contato com a realidade, está em condições de bem apreciar os motivos ocorrentes de oportunidade e conveniência na prática de certos atos, que seria impossível ao legislador, dispondo na regra jurídica - lei - de maneira geral e abstrata, prover com justiça e acerto. Só os órgãos executivos é que estão, em muitos casos, em condições de sentir e decidir administrativamente o que convém e o que não convém ao interesse coletivo" (STJ, 2003).

Com base nesses fundamentos, o Poder Judiciário reconheceu a impossibilidade financeira do Município não interferindo na sua esfera de decisão, preservando, portanto, o interesse da localidade em que se pleiteava a cessão de um imóvel para abrigo de menores.

É importante destacar que, no caso descrito, o Poder Judiciário não considerou necessário que os menores carentes dispusessem de local adequado. Pelo contrário, apenas reconheceu a impossibilidade financeira do Município e não impôs a obrigação judicial, respeitando as suas possibilidades fáticas e financeiras. Veja-se que, nesse caso, não se discutiu direito fundamental algum, mas apenas a ausência de recursos.

Ainda, acerca da reserva do possível, o Estado do Mato Grosso do Sul havia sido condenado parcialmente ao pagamento de indenização a um preso do sistema 
carcerário estadual que se sentiu lesado em razão da superlotação do presídio. $\mathrm{Na}$ ocasião, o Estado do Mato Grosso do Sul recorreu da decisão alegando que o Estado se empenha para melhorar as condições do sistema carcerário, sempre dentro da possibilidade de reserva orçamentária.

Nesse caso, o Tribunal de Justiça do Mato Grosso do Sul acolheu os argumentos do Estado, indicando que, em nenhum momento, houve descaso com o sistema prisional, mas, em decorrência da impossibilidade financeira, não teria sido possível melhorar as condições dos detentos. Assim, acolheu os argumentos da reserva do possível e rejeitou o pedido de indenização do Autor da ação:

A meu juízo, portanto, a pretensão de ser o preso indenizado não se revela
razoável, pois a cominação desta "reparação moral" equivale a constranger
o Estado a destinar mais recursos para o sistema prisional do que o
determinado no orçamento, que pode até ser insuficiente, porém o possível.
Ademais, em nada irá resolver o problema do apelante, tampouco amenizar
seu sofrimento por ter que conviver com excesso de pessoas em uma
mesma cela, em condições, na maioria das vezes, degradantes (TJ-MS,
2007).

Em caso semelhante, o mesmo Tribunal de Justiça do Mato Grosso do Sul reforçou o entendimento de que nos casos em que se trata de sistema carcerário, deve ser observada a cláusula da reserva do possível:

\footnotetext{
Por força do princípio da reserva do possível, o Estado está obrigado a cumprir suas obrigações legais até o limite de suas possibilidades financeiras e orçamentárias. [...] Não deve o Estado ser condenado a pagar a nenhum preso indenização por danos morais, advindos de superpopulação carcerária, se está ele buscando melhorar o sistema prisional do estabelecimento penal, onde se encontra o detento recolhido, dentro de suas possibilidades financeira e orçamentária" (TJ-MS, 2006).
}

Verifica-se, portanto, que a reserva do possível não é aplicável indistintamente em relação a qualquer alegação do poder público de indisponibilidade de recursos financeiros. Pelo contrário, conforme se demonstrou no presente artigo, a jurisprudência brasileira tem se posicionado de forma distinta a depender do direito envolvido.

\section{CONSIDERAÇÕES FINAIS}


Atos de Pesquisa em Educação - ISSN 1809-0354

Blumenau, v. 13, n.1, p.66-84, jan./abr. 2018

DOI: http://dx.doi.org/10.7867/1809-0354.2018v13n1p66-84

Até o momento, segundo os dados analisados no presente artigo, o Poder Judiciário não só tem rejeitado os argumentos do poder público, como determinado a imediata efetivação do direito sob pena de violação ao texto constitucional. No entanto, mesmo que as decisões analisadas demonstrem que a educação é tratada com prioridade e vem ganhando destaque em relação a outros direitos envolvidos, é preciso apontar que a "cláusula da reserva do possível" ganha centralidade nas justificativas do poder público visando justificar o não cumprimento de determinados preceitos legais. Portanto, considera-se que existe a possibilidade latente de que a cláusula da reserva do possível encontre guarida nas decisões pertinentes à garantia do direito à educação, restando à sociedade a vigilância constante para que a efetivação de direitos conquistados não seja burlada.

No campo das discussões e das interpretações legais, caso a cláusula da reserva do possível seja amplamente aceita no campo educacional, tornando-se matéria jurisprudencial, o poder judiciário pode tornar-se legitimador da inexecução das responsabilidades públicas. Situada no campo frágil das políticas públicas sociais, a educação fica à mercê dos compromissos e das responsabilidades dos gestores e da interpretação das Cortes Brasileiras. Ao cidadão comum resta a vigília constante para que seus direitos não sejam usurpados em razão de justificativas administrativas validadas pelo poder judiciário.

\section{SIMONE DE FÁTIMA FLACH}

Doutora em Educação pela Universidade Federal de São Carlos - UFSCar. Docente do Programa de Pós-Graduação em Educação da Universidade Estadual de Ponta Grossa -UEPG.

\section{AMANDA CRISTHINA FLACH}

Advogada. Mestre em Ciências Sociais Aplicadas pela Universidade Estadual de Ponta Grossa - UEPG.

\section{REFERÊNCIAS}

BRASIL. Constituição (1988). Constituição da República Federativa do Brasil. Brasília, DF: Senado, 1988. 
Atos de Pesquisa em Educação - ISSN 1809-0354

Blumenau, v. 13, n.1, p.66-84, jan./abr. 2018

DOI: http://dx.doi.org/10.7867/1809-0354.2018v13n1p66-84

BRASIL. Lei No 9.394, de 20 de dezembro de 1996. Estabelece as diretrizes e bases da educação nacional. Diário Oficial [da] República Federativa do Brasil, Poder Legislativo, Brasília, DF, 23 dez. 1996. Seção 1, n. 248, p. 27833-27841.

CURY, C. R. J. Legislação educacional brasileira. 2. ed. Rio de Janeiro: DP\&A, 2002.

GRAMSCI, A. Carta à Tatiana Schucht, em 07 de setembro de 1931. In:

Cartas do Cárcere (1931 - 1937). v. 2. Rio de Janeiro: Civilização Brasileira, 2005. p. $82-85$.

MÂNICA, F. B. Teoria da reserva do possível: direitos fundamentais a prestações e a intervenção do poder judiciário na implementação de políticas públicas. Revista eletrônica de direito administrativo econômico, Salvador, n. 25, 2011. Disponível em: <http://www. direitodoestado.com/revista/REDAE-25-ABRIL-2011-FERNANDOBORGES-MANICA.pdf>. Acesso em: 20 fev. 2016.

NEVES, L. M. W. Educação e política no Brasil de hoje. 2 ed. São Paulo: Cortez, 1999.

REALE, M. Modalidades do direito subjetivo. In: direito. 16. ed. São Paulo: Saraiva, 1988. p. 261-271. Lições preliminares de

SARLET, I. W. A eficácia dos direitos fundamentais: uma teoria geral dos direitos fundamentais na perspectiva constitucional. 11. ed. Porto Alegre: Livraria do Advogado, 2012.

SILVA, C. E. M. O direito à educação face à reserva do possível: a importância dos instrumentos de controle social. Jornal de Políticas Educacionais, Curitiba, n. 9, p. 41-50, jan./jun. 2011.

SOUZA, L. D. F. de. Reserva do possível e o mínimo existencial: embate entre direitos fundamentais e limitações orçamentárias. Âmbito Jurídico, Rio Grande, XVI, n. 116, set 2013. Disponível em: <http://ambitojuridico.com.br/site/?n_link=revista_artigos_leitura\&artigo_id=13621\&revista_cadern o=4>. Acesso em: 15 mar. 2016.

\section{STF. MEDIDA CAUTELAR EM ARGÜIÇÃO DE DESCUMPRIMENTO DE}

PRECEITO FUNDAMENTAL: ADPF 45 MC/DF. Relator: Ministro Celso de Mello, DJ: 29/04/2004. JusBrasil, 2004. Disponível em:

<http://stf.jusbrasil.com.br/jurisprudencia/14800508/medida-cautelar-em-arguicao-dedescumprimento-de-preceito-fundamental-adpf-45-df-stf>. Acesso em: 20 fev. 2016.

STJ. RECURSO ESPECIAL: REsp 208893 PR 1999/0026216-6. Relator: Ministro Franciulli Netto. DJ: 19/12/2003. JusBrasil, 2003. Disponível em: $<$ http://stj.jusbrasil.com.br/jurisprudencia/7381735/recurso-especial-resp-208893-pr1999-0026216-6/relatorio-e-voto-13044365>. Acesso em: 20 fev. 2016. 
Atos de Pesquisa em Educação - ISSN 1809-0354

Blumenau, v. 13, n.1, p.66-84, jan./abr. 2018

DOI: http://dx.doi.org/10.7867/1809-0354.2018v13n1p66-84

STJ. RECURSO ESPECIAL: REsp 208893 PR 1999/0026216-6. Relator: Ministro Franciulli Netto. DJ: 19/12/2003. JusBrasil, 2003. Disponível em:

$<$ http://stj.jusbrasil.com.br/jurisprudencia/7381735/recurso-especial-resp-208893-pr1999-0026216-6/relatorio-e-voto-13044365>. Acesso em: 20 fev. 2016.

STJ. RECURSO ESPECIAL: Resp 1185474 SC 2010/0048628-4. Relator: Ministro Humberto Martins. DJ: 20/04/2010. JusBrasil, 2010. Disponível em <https://stj.jusbrasil.com.br/jurisprudencia/9119367/recurso-especial-resp-1185474sc-2010-0048628-4/inteiro-teor-14265399?ref=juris-tabs>. Acesso em: 20 fev. 2016.

TJ-MS. APELAÇÃO CIVEL: AC 3222 MS 2006.003222-5. Relator: Des. Joenildo de Sousa Chaves, DJ: 21/09/2006. JusBrasil, 2006. Disponível em: <http://tjms.jusbrasil.com.br/jurisprudencia/4020946/apelacao-civel-ac-3222/inteiro-teor12154702>. Acesso em: 20 fev. 2016.

TJ-MS. APELAÇÃO CIVEL: AC 16735 MS 2005.016735-0. Relator: Des. Joenildo de Sousa Chaves, DJ: 08/05/2007. JusBrasil, 2007. Disponível em: <http://tjms.jusbrasil.com.br/jurisprudencia/4052862/apelacao-civel-ac-16735/inteiro-teor12178334>. Acesso em: 20 fev. 2016

TJ-RS. AGRAVO DE INSTRUMENTO: AI 70062590989. Relator: Liselena Schifino Robles Ribeiro, DJ: 13/11/2014. JusBrasil, 2014. Disponível em: <https://tjrs.jusbrasil.com.br/jurisprudencia/152096008/agravo-de-instrumento-ai70062590989-rs>. Acesso em: 20 fev. 2016.

VENOSA, S. S. Introdução ao estudo do Direito: primeiras linhas. 2 ed. São Paulo: Atlas, 2009.

WANG, D. W. L. Escassez de recursos, custos dos direitos e reserva do possível nas decisões do STF. Revista Direito GV, São Paulo. v. 4, n. 2. 2008. p. 539-568. 